\title{
TICARET YAPMANIN ÖNÜNDE ENGELLER VE KASTAMONU
}

\author{
Serkan DiLEK ${ }^{1}$
}

Özet:

Günümüzde girişimcilik ekonomi açısından en önemli üretim faktörü haline gelmiştir. Diğer üretim faktörlerini bir araya getirip üretime yönlendiren girişimciler ekonomik kalkınma ve büyüme açısından büyük önem arz etmektedir. Bu nedenle kalkınmasını hızla gerçekleştirmek isteyen Kastamonu için girişimcilerin desteklenmesi gereklidir. Fakat girişimciler ticaret yaparken pek çok engelle karşılaşmaktadır. Bu çalışmada Kastamonu'da girişimcilerin karşılaştıkları zorlukların araştırılması amaçlanmıştır. Finansa ulaşma zorlukları, yetersiz eğitimli işgücü, Kamu sağlığı problemleri ve Ulaştırma sistemi yetersizlikleri temel sorunlar olarak ortaya çıkmıştır. Çalışmanın sonunda Kastamonu ticaret hayatının gelişmesi için çözüm önerileri ele alınmıştır.

Anahtar Kelimeler: Girişimcilik, Kastamonu Ekonomisi,

JEL Kodu: L26, L21, M21

\section{DIFFICULTIES TO DOING BUSINESS IN KASTAMONU}

\begin{abstract}
:
Nowadays, Entrepreneurship becomes the most important production factor for economy. Entrepreneurs who gather other production factors to produce goods and services are very important for both economic development and growth. Because of this reason it is needed to support entrepreneurs in Kastamonu which wants to be developed rapidly. However entrepreneurs meet with many difficulties while doing business. In this study I aim to search difficulties through doing business in Kastamonu. Access to financing, Poorness in public health, inadequate educated work force and inadequate transportation system are revealed as main problems. At the end of the study proposals to develop Kastamonu business are given.
\end{abstract}

Keywords: Entrepreneurship, Kastamonu Economics

JEL Codes: L26, L21, M21

\footnotetext{
${ }^{1}$ Kastamonu Üniversitesi İktisadi ve İdari Bilimler Fakültesi, Doç.Dr., serkan.dilek@gmail.com
} 


\section{GİIȘ}

Ekonomik gelişmeyi sağlayan en önemli etmenlerden birinin girişimcilik olduğu genel kabul görmektedir. Kalkınma ve büyüme gibi ekonomik hedeflerin gerçekleştirilmesi için girişimcilerin desteklenmesi, girişimcilerin de etkin üretim faaliyetlerini gerçekleștirmesi gerekmektedir. Sınırlı doğal kaynaklara sahip olmalarına rağmen başarılı biçimde iş kuran ve yürüten girişimcilere sahip oldukları için ekonomik amaçlarını gerçekleştiren ülkelere rastlanmaktadır. Girişimciler kurdukları işi yürütürken hem riske katlanmakta hem de zorluklara göğüs germektedir. Girişimcilerin önünde önemli zorluklar ve engeller bulunmaktadır. Girişimcilerin karşılaştıkları zorlukları minimize etmek, işlerini kolaylaştırmak ve desteklemek ekonomik amaçlarını gerçekleştirmek isteyen ülkeler için önem taşımaktadır.

Sosyo-ekonomik gelişmişlik açısından Türkiye, 81 il arasında ortalamanın biraz altında yer almaktadır. Gelişme ve kalkınma açısından Kastamonu'nun hedeflerine ulaştı̆ıını söylemek kolay değildir. Kastamonu il merkezinde yoğun biçimde kamu kurumlarına ait yatırımların bulunduğu gözlenmektedir. Bu açıdan Kastamonu sakinlerinin girişimcilik yapılarının ortaya çıkarılması, girişimcilerin iş kurarken ve yürütürken karşılaştıkları zorlukların belirlenerek çözüm yollarının araştırılması gereklilik arz etmektedir. Çalışma, Kastamonu iş adamlarının ticaret yaparken karşılaştıkları zorlukların belirlenmesi bakımından literatürde ilktir. İleride bu çalışmaların benzeri TR82 ve Karadeniz bölgesi illerinde uygulanarak genişletilebilir ve bölge kalkınmasına fayda sağlayabilir.

\section{GIRIŞiMCI, GIRIŞiMCILIIK TANIMLARI}

Girişimciliğin literatürde çeşitli tanımları bulunmaktadır. Küçük (2015:29), girişimciliği "bir işletmenin kurulması, yönetsel süreçlerin işletilmesi, üretim ve pazarlamaya yönelik tüm risklerin üstlenilmesi gibi bir işin kurulması ve yürütülmesine ilişkin faaliyetler bütünü" olarak tanımlamaktadır. Ayrıca "değişik üretim faktörlerini bir araya getirip risk alan ve bu riskin sonuçlarına katlanan kişi”" veya "işi soyut halden alıp somut hale dönüştürüp gerçekleştiren kişi”" olarak da tanımlanabilir (Top, 2006:5). Yıldırım vd (2011:190) ise girişimciyi "kar ve riski dengeleyerek yeni düşünceler geliştiren ve bu düşünceleri uygulama yeteneğine, gücüne sahip kişi ve kuruluşlar" olarak tanımlamaktadır. Literatürde girişimciliğe ait pek çok tanıma rastlanabilir (Top, 2006). Girişimcilik ülke veya bölge ekonomisine çok önemli pozitif katkılar sağlamakta ve diğer kişilere istihdam imkanı sağlamaktadır (Top vd, 2012:935). Bu nedenle çeşitli ülkeler gençleri, bir kariyer alternatifi olarak girişimciliği seçmeleri konusunda teşvik etmeye, girişimcilik eğitimi vermeye yönelmektedir (Akın ve Demirel, 2015:16). Girişimcilik eğitimi ve teşviklere rağmen zorluk ve risklerden dolayı bireyleri girişimciliğe yöneltmek kolay değildir.

\section{TÍCARET YAPMA ENGELLERİ}

Girişimcilik dünyanın en zor mesleklerinden biridir. Bir girişimcinin başarılı olabilmesi için çalışanlar, yöneticiler, rakipler, tedarikçiler, devlet kurumları ve diğer çevre unsurları ile başarılı biçimde iletişim kurabilmesine, zorluklardan yılmamasına bağlıdır. Girişimcilerin karşılaştıkları zorluklar piyasaya giriş yapmadan önce karşılaşılan ve piyasaya giriş yaptıktan sonra karşılaşılan zorluklar olmak üzere ikiye ayrılabilir.

Piyasaya giriş yapmadan önce girişimcilerin karşılaştıkları engeller literatürde piyasaya giriş engelleri olarak yer almaktadır. Giriş engelleri kavramını iktisat literatürüne Clark, Schumpeter ve Bain kazandırmıştır (Türkkan, 2001:264). Giriş engellerini Bain, endüstride yerleşik firmalara kıyasla endüstriye yeni girecek potansiyel firmaların dezavantajlı durumda olmasına yol açan öğeler olarak tanımlamıştır (Davut, 2002:127). Piyasaya giriş engelleri içsel ve dişsal olmak üzere ikiye ayrılır. İçsel (endojen) giriş engelleri piyasada mevcut firmaların, potansiyel firmaların piyasaya girişlerini zorlaştırması iken dışsal (eksojen) giriş engelleri ise yerleşik firmalardan kaynaklanmayan piyasa yapısından kaynaklanan giriş engelleridir (Gable vd, 1995:211; Dilek ve Top, 2012:776).

Firmalar piyasaya giriş yaptıktan sonra da piyasa yapısı, iç ve dış çevrenin etkileri gibi nedenlerden dolayı da zorlanabilir. Vergi oranları, makro ekonomik göstergeler, politik istikrarsızlık, rüşvet ve yolsuzluk, suç yaygınlığı gibi nedenler firmanın amaçlarına ulaşmasının önünde bulunan engeller olarak ortaya çıkmaktadır.

Dünya Ekonomik Forumunun yayınladığı 2015-2016 Küresel Rekabetçilik raporunda ülkeler rekabetçi güçlerine göre sıralanmıştır. Türkiye'nin 51. Sırada yer aldığ 1 çalışmada ayrıca her ülkede ticaret yapmanın önünde yer alan zorluklar ele alınmıştır. Çalışmaya göre Türkiye'de ticaret yapmanın önünde bulunan zorluklar Tablo 1'de yer almaktadır (WEF, 2015).

Tablo 1. Türkiye'de Ticaret Yapmanın Önünde Engeller 


\begin{tabular}{|l|l|}
\hline Engeller & Yüzde \\
\hline Vergi Oranları & $\% 14$ \\
\hline Finansa Ulaşım & $\% 12.2$ \\
\hline Yetersiz Eğitimli İşgücü & $\% 12$ \\
\hline Döviz Kuru Regülasyonları & $\% 11.3$ \\
\hline Vergi Düzenlemeleri Karmaşıklı̆̆1 & $\% 8.4$ \\
\hline Etkinsiz Bürokrasi & $\% 7.1$ \\
\hline Yetersiz Altyapı & $\% 6.6$ \\
\hline Politik İstikrarsılık & $\% 6.2$ \\
\hline Etkinsiz İnnovasyon Kapasitesi & $\% 5.5$ \\
\hline Kısıtlayıcı İşgücü Regülasyonları & $\% 5.2$ \\
\hline Enflasyon & $\% 5.1$ \\
\hline Zayıf İş Etiği & $\% 2.3$ \\
\hline Rüşvet ve Yolsuzluk & $\% 1.5$ \\
\hline Devlet İstikrarsılığ1- Çatışma & $\% 1.3$ \\
\hline Zayıf Kamu Sağlığ1 & $\% 0.9$ \\
\hline Suç ve Hırsılık & $\% 0.3$ \\
\hline
\end{tabular}

Kaynak: WEF, 2015

\section{KASTAMONU TİCARET HAYATININ ÖNÜNDEKİ ENGELLER}

Vergi oranları: Kastamonu vergi oranlarının ülkedeki diğer illere göre bir farklılığı yoktur. Türkiye'de vergi oranlarının yüksek olarak bulunması aynı zamanda Kastamonu'da da vergi oranlarının yüksek olduğu anlamına gelmektedir.

Finansa Ulaşım: Kastamonu'da sermaye birikiminin yeterli olmaması girişimcilerin önündeki önemli engellerden biridir. 2011 yılında Türkiye'de kişi başına Gayri safi Katma Değer 9244\$ iken Kastamonu'nun da içinde bulunduğu TR82 bölgesinde bu değer sadece 6594\$'dır (TUIKK, 2014:9). Dilek ve Kandemir (2013:16), Kastamonu Turizm sektörünün zayıf yönlerinden birinin sermaye birikimi yetersizliği olduğunu ortaya çıkarmıştır.

Yetersiz Eğitimli İşgücü: Kastamonu Üniversitesi’nin 2006 yılında kurulmuş olması nedeniyle henüz gelişimini tamamlamamıştır, ancak hızla gelişmektedir. 2016 yılında Kastamonu Üniversitesi’nde 36 Profesör, 55 Doçent ve 196 Yardımcı Doçent görev yapmakta; toplam öğrenci sayısı ise 23817 kişidir (Kastamonu Üniversitesi, 2016). Kastamonu ve Türkiye'de üniversitelerin gelişimine bağlı olarak eğitimli işgücü zaafiyeti ortadan kalkacaktır. Yakışık ve Çetin (2014) yaptıkları çalışmada orta öğretim okullaşma oranının ekonomik büyüme üzerinde anlamlı ve pozitif yönlü etkisi olduğunu ortaya çıkarmıştır. Tablo 2'de Kastamonu'nun da içinde bulunduğu TR82 bölgesinde işgücü istatistikleri verilmiştir. Görüldüğü gibi işgücü içerisinde yükseköğrenim görmüşlerin payı oldukça düşüktür. Türkiye'de 2013 yılında işgücünün \%19'u yükseköğrenim görmüş kişiler iken TR82 bölgesinde 2013 yılında bu oran sadece \%13'dür (TUIK, 2014:145).

Tablo 2. TR82 Bölgesi İşgücü İstatistikleri (.000 Kişi)

\begin{tabular}{|l|l|l|l|l|l|}
\hline Yıl & Toplam & $\begin{array}{l}\text { Okuma yazma } \\
\text { Bilmeyen }\end{array}$ & $\begin{array}{l}\text { Lise Altı } \\
\text { Ĕgitim }\end{array}$ & $\begin{array}{l}\text { Lise ve Dengi } \\
\text { Okul }\end{array}$ & $\begin{array}{l}\text { Yüksek } \\
\text { Öğretim }\end{array}$ \\
\hline 2011 & 344 & 33 & 216 & 55 & 40 \\
\hline 2012 & 324 & 24 & 208 & 51 & 40 \\
\hline 2013 & 281 & 11 & 182 & 51 & 37 \\
\hline
\end{tabular}

Kaynak: TUIK (2014:145).

Döviz Kuru Regülasyonları: Döviz kurlarında meydana gelen değișimler gerek ihracat gerekse ithalatı etkilemektedir (Kesgingöz, 2015). Kastamonu işletmeleri de ithalat yoluyla girdi temin ederken ihracat yoluyla da mallarını sattıkları için döviz kuru değişikliklerinden etkilenmektedirler (İnançlı ve Konak, 2011). Ayrıca Kastamonu'da turizm giderek gelişmekte; yurtiçi ve yurtdışından turistler giderek daha yoğun olarak Kastamonu'yu tercih etmektedir. Turizm tercihleri ile döviz kuru arasında da ilişki olduğu amprik çalışmalarla desteklenmektedir (İnançlı vd. 2012:3). Türkiye'de dalgalı döviz kuru uygulanırken kimi zaman piyasaya Merkez Bankası tarafından müdahalelerde bulunulmaktadır. Dalgalı döviz kurunun zayıf yönü istikrarsız seyir izlemesidir. İstikrarsızlık ise sadece Kastamonu değil Türkiye'deki tüm firmaları olumsuz etkileyebilmektedir. 
Vergi Düzenlemeleri Karmaşıklı̆̆ı: Karlarını maksimize etmek isteyen firmalar için vergiler hoş karşılanmamaktadır. Vergilerin oranı ve tutarı dışında kamusal düzenlemeler de firmaların performansını belirlemekte ve iş yapma isteklerini cesaretlendirmekte veya iş yapmaktan caydırmaktadır. Genel olarak modern vergi sistemlerinin çok karmaşık hale geldiği ve topluma maliyet yüklediği varsayılmaktadır (Karabacak, 2013).

Etkinsiz Bürokrasi: Devlet iktisadi hayat içinde farklı biçimlerde yer alabilmektedir. Firmalar da diş çevre unsuru olarak devlet ile iletişim halindedirler. Genelde devlet bürokrasisi ve devletin ekonomiye müdahaleleri kişisel özgürlükleri olumsuz yönde etkilemek suretiyle firmaların işini zorlaştırmakta ve piyasa sistemini sekteye uğratmaktadır (Arslan, 2010:112).

Yetersiz Altyapı: Firmalar faaliyetlerini başarılı biçimde sürdürebilmeleri için su, elektrik, doğalgaz, ulaşım altyapılarının olması önem arz etmektedir. 2007 yılında Kastamonu Organize sanayi bölgesi kurulmuştur, Tosya ve Taşköprü organize sanayi bölgeleri kuruluş aşamasındadır (TUİK, 2014:XIII). Ulaşım altyapısında olan sorunlar ise Kastamonu Havalimanı'nın kurulması, Ilgaz Tüneli inşaatı, Sahil yolu inşaatı gibi yatırımlar ile çözülmeye çalışılmaktadır. Dilek ve Kandemir (2013), ulaşımın Kastamonu Turizm sektörünün zayıf yönü olduğunu ortaya koymuştur. Halis ve Altmışev (2015:9), girdi koşullarının (eğitimli işgücü, sermaye, doğal kaynaklar, fiziki ve bilgi altyapısından oluşan koşullar) rekabet avantajı sağladığı yolundaki Porter'in çalışmalarına atıflarda bulunmaktadır. Tablo 3'de Kastamonu ilinde mevcut yol uzunlukları verilmiştir. İl sınırları içinde otoyol ve demiryolu bulunmaması ulaşım altyapısında sorun olduğunu göstermektedir.

Tablo 3. Kastamonu Yol Uzunlukları (KM)

\begin{tabular}{|l|l|l|l|l|}
\hline Yıl & $\begin{array}{l}\text { İ ve Devlet } \\
\text { Yolu }\end{array}$ & Otoyol & Köy Yolu & Demir Yolu \\
\hline 2009 & 1306 & - & 9208 & - \\
\hline 2010 & 1306 & - & 9319 & - \\
\hline 2011 & 1306 & - & 9303 & - \\
\hline 2012 & 1300 & - & 9245 & - \\
\hline 2013 & 1301 & - & 9336 & - \\
\hline
\end{tabular}

Kaynak: TUIK (2014:136).

Bilgi teknolojilerinden ve internetten faydalanma, stratejik uygulamalar işletme faaliyetlerinin sürekliliği için önemli bir unsurdur (Sarışık ve Akova, 2006:130). Facebook, Twitter gibi sosyal medya uygulamaları Kobi'ler için bir firsat oluşturmuştur (Geçti ve Gümüş, 2014). Ancak Kastamonu firmalarının bu imkandan yeterince faydalandıği söylenemez.

Politik Ístikrarsızlık: Yapılan ekonometrik çalışmalar politik istikrarsızlık ile ekonomik büyüme arasındaki ters yönlü ilişkiyi doğrulamaktadır (Şanlısoy ve Kök, 2010). 7 Haziran 2015 yılı seçimlerinde tek başına iktidar çıkmaması ve partilerin birbirleri arasında koalisyon anlaşmasına varamadılar. 1 Kasım 2015 yılı seçimlerine kadarki süreçte ortaya çıkan politik istikrarsızlık Kastamonu firmalarını da olumsuz yönde etkilemiştir. Politik istikrar, devlet teşvikleri ve vergi uygulamaları açısından önemlidir ve firmaları bu yönden etkileyebilir. Eleren (2006:408) firmaların kuruluş yeri seçiminde devlet teşvikleri en önemli faktörlerden biri olduğunu ortaya koymuştur.

Etkinsiz Innovasyon Kapasitesi: Günümüzde Ar-ge ve innovasyon ekonominin vazgeçilmez unsurlarından olmuştur (Dilek, 2016:89). Akay ve Türkay (2014:38-39) firmanın sahip olduğu teknoloji düzeyinin artması durumunda firmaların rekabet güçlerini artıracağını belirtmiştir. Gülmez ve Yardımcığlu (2012), Ar-Ge harcamaları ile ekonomik büyüme değişkenleri arasında karşılıklı olarak anlamlı ilişki bulmuşlardır. Kastamonu Üniversitesi'nin giderek artan sayıda patent alıyor olması innovasyon kapasitesini olumlu yönde etkileyeceği düşünülmektedir. Mühendislik ve Mimarlık Fakültesi de yeni yeni gelişmeye başlamıştır. Mevcut Kastamonu firmalarının da innovasyon kapasitelerinin yeterli olmadığı görülmektedir.

Kısıtlayıcı İşgücü Regülasyonları: İşgücü piyasalarında gerçekleştirilen regülasyonlar esnekliği ortadan kaldırmaktadır. Türkiye işgücü piyasalarının iş ve sosyal güvenlik yasaları ile regüle edildiği ve görece olarak OECD ülkelerine göre daha katı olduğu yapılan çalışmalarla ortaya çıkarılmıştır (Aykaç ve Çiftçi, 2011:113). Yasalar ve düzenlemeler Kastamonu için de geçerlidir. Kastamonu işgücü piyasası için önemli sorunlardan biri de ilden yoğun olarak büyükşehirlere (özellikle İstanbul'a) gerçekleşen göçtür. 2011-2012 ve 2012-2013 dönemlerinde uzun zaman sonra Kastamonu'nun aldığı göç, verdiği göç rakamlarının üzerine çıkmıştır (TUİK, 2014:92).

Enflasyon: Türkiye'de 2015 yılı enflasyonu (TÜFE) \%8.81 olarak gerçekleşmiştir. 1970-2000 y1lları arasında enflasyon \%30 ile \%100 arasında gerçekleştiği dikkate alınırsa görece daha düşüktür. Ancak firmaların 
iş yapabilmesi açısından enflasyonun \%5'in altına çekilmesi faydalı olacaktır. Berber ve Artan (2004), enflasyonun ekonomik büyümeyi olumsuz etkilediğini; enflasyon oranında \%10'luk bir artışın ekonomik büyümeyi \%1.9 oranında düşürdüğünü; enflasyondan ekonomik büyümeye doğru tek yönlü Granger nedensellik olduğunu ortaya çıkarmışlardır.

Zayıf İş Etiği: Halis vd (2007:130) iş etiğinin literatürde (McNamara) işyerinde doğru ile yanlışın ayırt edilerek doğru olanı yapmak için oluşturulan kural ve ilkeler kümesi olarak tanımlandığını belirtmiştir. İş etiğinin zayıf olması ortaklıkları, birlikte iş yapılmasını, ticaret yapılmasını zorlaştırmaktadır. Firmalar ticaret yaparken dış çevre unsuru olan diğer firmalarla tedarikçi veya rakip olarak etkileşimde bulunurlar. Diğer firmaların iş etiğine uygun olmayan davranışları ticareti olumsuz yönde etkilemektedir. Ancak Kastamonu'nun küçük bir il olması ve kişiler arasında birebir iletişimin güçlü olması iş etiğine uygun olmayan davranışların azalmasını sağlamaktadır.

Rüşvet ve Yolsuzluk: Rüşvet, ekonomide kaynakların kötü kullanımını, gelir dağılımında bozulma, bazı kişilere haksız gelir transferine neden olmaktadır (Çoban, 1999:187). Firmaların bir kısmı rüşvet sayesinde kazanımlar elde etse bile özellikle piyasaya yeni giren firmalar rüşvet ve yolsuzluktan olumsuz yönde etkilenmektedir.

Devlet Ístikrarsızlı̆̆g- Çatışma: 7 Haziran 2015 tarihli seçimlerde politik istikrarsızlığa neden olacak bir sonucun çıkması sonucunda Güneydoğu Anadolu bölgesinde ve İstanbul, Ankara gibi Büyükşehirlerde terör faaliyetleri ortaya çıkmıştır. Ancak Karadeniz bölgesi ve Kastamonu'da Devlet istikrarsızlığı ve terör olayları meydana gelmemiştir. Firmaların Kastamonu'da faaliyetlerini zorlaştıracak bir terör ortamı bulunmamaktadır. Zorlu ve Hacıoğlu (2012) çatışma ortamının firma performansları ve verimlilik üzerine negatif yönlü ilişkisini ortaya koymuştur.

Zayıf Kamu Sağlığg: Kastamonu'nun en önemli sorunlarından biri olarak görülen Kamu sağlığı probleminin çözümü için 400 yataklı Kamu hastanesi inşaati başlamış; Hacettepe Üniversitesi'ne bağlı Tıp Fakültesi, Kastamonu Üniversitesi'ne devredilmiştir. TUİK (2014:143)'e göre Kastamonu'da 2012 yılında toplam (özel ve sağlık bakanlığg kurumları toplamı) 19 sağlık kurumu ve bu kurumlara ait 1254 yatak bulunmaktadır.

Suç ve Hırsızlık: Suç oranının yüksekliği, hırsızlık ve soygun olayları ticaret yapmanın önündeki engellerdir. Kastamonu suç olaylarının düşük görüldüğü illerden biri olması nedeniyle şanslıdır. Tablo 4'de Kastamonu ve Türkiye'de işlenen suçlar nedeniyle cezaevine giren hükümlüler verilmiştir. 2011 ve 2012 yılında Kastamonu Nüfusunun Türkiye nüfusuna oranı 0.0048 'dir. Oysa Kastamonu'da Hırsızlık ve Yağma suçlarından cezaevine giren hükümlü sayısının Türkiye'de aynı suçtan cezaevine giren kişi sayısına oranı çok daha düşüktür. Bu sonuçta Hırsızlık ve yağma suçları bakımından Kastamonu'nun Türkiye ortalamasına göre daha güvenilir bir şehir olduğunu ortaya koymaktadır.

Tablo 4. Hırsızlık ve Yağma Suçlarından Cezaevine Giren Hükümlü Sayıları

\begin{tabular}{|l|l|l|l|}
\hline Y11 & $\begin{array}{l}\text { Kastamonu'da } \\
\text { Hirsızlık Yağma } \\
\text { suçları }\end{array}$ & $\begin{array}{l}\text { Türkiye'de } \\
\text { Hirsızlı } \\
\text { Yağma Suçlar1 }\end{array}$ & $\begin{array}{l}\text { Kastamonu/Türkiye } \\
\text { Hırsılı } \\
\text { Suçlar1 }\end{array}$ \\
\hline 2010 & 14 & 8325 & 0.0017 \\
\hline 2011 & 27 & 8670 & 0.0031 \\
\hline 2012 & 26 & 15625 & 0.0017 \\
\hline
\end{tabular}

Kaynak: TUIK (2014:181).

\section{SONUÇ}

Ekonomik büyüme ve kalkınma hedeflerine ulaşmak için özel sektörün desteklenmesi, iş yapabilmelerinin önündeki engellerin kaldırılması gereklidir. Ekonomik büyümenin tüm yükünü devletin üzerine alması artık kabul görmemekte, devletin görevinin özel kesimin rekabet gücünü artıracak biçimde ihtiyacı olan desteklerin verilmesi olduğu düşünülmektedir. Çalışmada Kastamonu ticaret hayatında firmaların karşılaşabilecekleri olası sorunlar ele alınmıştır. Finansa ulaşma zorlukları, yetersiz eğitimli işgücü, kamu sağlığı problemleri, ulaştırma sistemi yetersizlikleri Kastamonu ticaret hayatında firmaların karşılaştıkları en önemli sorunlar olarak karşımıza çıkmaktadır. Yine de Kastamonu ticaret hayatı üzerinde amprik çalışmaların yapılması ve sorunların tespit edilmesine ihtiyaç bulunmaktadır. 


\section{KAYNAKÇA}

Akay, Bayram ve Türkay, Oğuz (2014), "Uluslararasılaşmış Bir Sektörde Rekabet Gücü Neye Bağlıdır? Araç Kiralama İşletmeleri Üzerine Bir Araştırma”, Kastamonu Üniversitesi İİBF Dergisi, 5, 37-54

Akın, Bahadır ve Demirel, Yavuz (2015), "Entrepreneurship Education and Perception Change: The Preliminary Outcomes of Compulsory Entrepreneurship Course Experience In Turkey”, Selçuk Üniversitesi Sosyal Bilimler Enstitüsü Dergisi, 34, 15-16.

Arslan, Nagehan Talat (2010), “Klasik Neo Klasik Dönüşüm Süreci: Yeni Kamu Yönetimi” CÜ İktisadi ve İdari Bilimler Dergisi, 11(2).

Aykaç, Gökhan ve Çiftçi, Cemil (2011), “OECD Ülkelerinde İşgücü Piyasası Regülasyonları ve Regülasyonlardaki Eğilimler”, Ekonomik Yaklaşım, 22(78), 91-118.

Berber, Metin ve Artan, Seyfettin (2004), "Enflasyon ve Ekonomik Büyüme İlişkisi: Türkiye Örneği”, Türkiye Ekonomi Kurumu Discussion Paper 2004:21.

Çoban, Orhan (1999), “Bir Siyasal Yozlaşma Türü Olarak Rüşvet ve Ekonomik Etkileri”, Atatürk Üniversitesi İktisadi ve İdari Bilimler Fakültesi Dergisi, 13(1), 173-195.

Davut, Lale (2002), Sanayi İktisadı Piyasa Yapısı Unsurları, İmaj Yayınevi

Dilek, Serkan (2016), "Enformasyon ve Bilgiye Dayalı Ekonomi”, Kastamonu Üniversitesi İktisadi ve İdari Bilimler Fakültesi Dergisi, 11, 87-91

Dilek, Serkan and Kandemir, Orhan (2013). "In the Process of Global Crisis The Importance of Tourism In Decreasing Regional Development Differences: An Evaluation of Kastamonu Province In Turkey”, International Journal of Management and Innovation, 5(1), 12-30

Dilek, Serkan ve Top, Seyfi (2012), "Is Setting Up Barriers to Entry Always Profitable For Incumbent Firms?”, Procedia Social and Behavioral Sciences, 58, 774-782.

Eleren, Ali (2006), "Kuruluş Yeri Seçiminin Analitik Hiyerarşi Süreci Yöntemi ile Belirlenmesi: Deri Sektörü Örneği”, Atatürk Üniversitesi İktisadi ve İdari Bilimler Fakültesi Dergisi, 20(2), 405-416

Gable, Myron; Topol, Martin T., Mathis, Stephen and Fisher Melvyn (1995), "Entry Barriers In Retailing”, Journal of Retailing and Consumer Services, 2(4), 211-221.

Geçti, Fatih ve Gümüş, Niyazi (2014), "Investigating The Facebook Applications and Their Impact On Customer Loyalty In The Turkish Mobile Telecommunication Industry”, International Journal of Business and Management, 9(5), 195-207.

Gülmez, Ahmet ve Yardımcığlu, Fatih (2012), "OECD Ülkelerinde Ar-Ge Harcamaları ve Ekonomik Büyüme İlişkisi: Panel Eşbütünleşme ve Panel Nedensellik Analizi (1990-2010).", Maliye Dergisi, 163, 335-353

Halis, Mine ve Altmışev, Sancar (2015), “Kırgızistan Çüy Bölgesi Süt Ürünleri Sektörünün Rekabet Analizi”, Kastamonu Üniversitesi İktisadi ve İdari Bilimler Fakültesi Dergisi, 6, 6-22.

Halis, Muhsin; Akowa, O ve Tagraf, H (2007), “The Relationship Between Ethics and Quality: Conflicts and Common Groups", Serbian Journal of Management, 2(2), 127-145

İnançlı, Selim; Ekici, Mehmet Sena ve Babacan, Adem (2012), “Gelen Yabancı Turist ve Yurtdışına Çıkan Yerli Turistler İle Kişi Başına Gelir Arasındaki Uzun Dönem İlişkisinin Belirlenmesi 1980-2011 Dönemi: Türkiye Örneği”, Sakarya İktisat Dergisi, 1(3), 1-19.

İnançlı, Selim ve Konak, Ali (2011), “Türkiye'de İhracatın İthalata Bağımlılığı: otomotiv Sektörü”, Eskişehir Osmangazi Üniversitesi İktisadi ve İdari Bilimler Fakültesi Dergisi, 6(2).

Karabacak, Yakup (2013), "Vergi Karmaşıklığı Modern Vergi Sistemlerinin Kaçınılmaz Sonu mudur?" Mali Çözüm İSMMO, 15-30.

Kastamonu Üniversitesi (2016), www.kastamonu.edu.tr 
Kesgingöz, Hayrettin (2015), "Döviz Kurundaki değişimin Türkiye-Kırgızistan Dış Ticaretine Etkisi:Var Analizi”, Kastamonu Üniversitesi İIBF Dergisi, 8

Küçük, Orhan (2015), Girişimcilik ve Küçük İşletme Yönetimi, Seçkin Yayınevi.

Sarışı1k, Mehmet ve Akova, Orhan (2006), "Seyahat Acentalarında İnternet Rolü ve Önemi Üzerine Bir Araştırma”, Kocaeli Üniversitesi Sosyal Bilimler Enstitüsü Dergisi, 12, 128-148.

Şanlısoy, Selim ve Kök, Recep (2010), "Politik İstikrarsızlık- Ekonomik Büyüme İlişkisi: Türkiye Örneği (1987-2006), Dokuz Eylül Üniversitesi İktisadi ve İdari Bilimler Fakültesi Dergisi, 25(1), 101-125.

Top, Seyfi; Çolakoğlu, Nurdan ve Dilek, Serkan (2012), "Evaluating Entrepreneurship Intentions of Vocational High School Pupils Basd On Self Efficacy Concept”, Procedia Social and Behavioral Sciences, 58, 934-943.

Top, Seyfi (2006), Girişimcilik Keşif Süreci, Beta Yayınları.

TUIK (2014), Seçilmiş Göstergelerle Kastamonu 2013, Yayın No:4270

Türkkan, Erdal (2001), Rekabet Teorisi ve Endüstri İktisadı, Turhan Kitapevi.

WEF (2015), The Global Competitiveness Report 2015-16

Yakışık, Harun ve Çetin, Ahmet (2014), "Eğitim, Sağlık ve Teknoloji Düzeyinin Ekonomik Büyüme Üzerindeki Etkisi: ARDL Sınır Test Yaklaşımı”, Sosyo Ekonomi, 21, January.

Yıldırım, Mehmet Halit; Demirel, Yavuz ve İçerli, Leyla (2011), “İşletme Sahibi Yöneticilerinin Girişimci Kişilik Özellikleri İle Girişimcilik Becerileri Arasındaki İlişkinin Tespiti: Aksaray Örneği”, Organizasyon ve Yönetim Bilimleri Dergisi, 3(2), 189-199.

Zorlu, Kürşat ve Hacıŏlu, Ümit (2012), “The Conflict Issue In International Business and The Global Leadership", Procedia Social and Behavioral Sciences, 41, 100-107 